\title{
Redes técnicas e mudanças territoriais: ampliação da concessão de eixos rodoviários à leste da Região Metropolitana do Rio de Janeiro.
}

Technical networks and territorial changes: the expansion of road axes to the east of the Metropolitan Region of Rio de Janeiro.

Réseaux techniques et changements territoriaux : l'élargissement de la concession des axes autoroutières dans l'est de la Région Métropolitaine de Rio de Janeiro

Redes técnicas y cambios territoriales: ampliación de la concesión de carreteras al este de la Región Metropolitana de Río de Janeiro.

\section{D'Jeanine Candido}

\section{(2) OpenEdition} Journals

\section{Edição electrónica}

URL: https://journals.openedition.org/espacoeconomia/21375

DOI: 10.4000/espacoeconomia.21375

ISSN: 2317-7837

\section{Editora}

Núcleo de Pesquisa Espaço \& Economia

\section{Refêrencia eletrónica}

D'Jeanine Candido, «Redes técnicas e mudanças territoriais: ampliação da concessão de eixos rodoviários à leste da Região Metropolitana do Rio de Janeiro.», Espaço e Economia [Online], 22 | 2021, posto online no dia 13 janeiro 2022, consultado o 13 agosto 2022. URL: http:// journals.openedition.org/espacoeconomia/21375 ; DOI: https://doi.org/10.4000/espacoeconomia. 21375

Este documento foi criado de forma automática no dia 13 agosto 2022. 


\section{Redes técnicas e mudanças territoriais: ampliação da concessão de eixos rodoviários à leste da Região Metropolitana do Rio de Janeiro.}

Technical networks and territorial changes: the expansion of road axes to the east of the Metropolitan Region of Rio de Janeiro.

Réseaux techniques et changements territoriaux : l'élargissement de la concession des axes autoroutières dans l'est de la Région Métropolitaine de Rio de Janeiro

Redes técnicas y cambios territoriales: ampliación de la concesión de carreteras al este de la Región Metropolitana de Río de Janeiro.

D'Jeanine Candido

\section{Introdução}

Os investimentos públicos e privados no desenvolvimento das atividades produtivas do petróleo no estado do Rio de Janeiro, a partir de 2006, desencadeou importantes transformações territoriais dos eixos viários e logísticos do estado. Essas transformações foram marcadas por uma dinamização e indução na ampliação de investimentos em diferentes setores, como o setor industrial e o imobiliário, devido às grandes expectativas criadas por grandes projetos, como o Comperj, e suas bases logísticas e de infraestrutura. Logo, com a tendência de aumento dos fluxos de capital, pessoas e mercadorias, houve a necessidade da construção e de reestruturação das rodovias que fornecessem base para a circulação e comunicação, ampliando a integração dos municípios na periferia metropolitana fluminense. 
2 Enfim, observamos que muitos investimentos foram alocados na construção ou melhorias em infraestruturas logísticas como portos, estradas, linhas de transmissão de energia e comunicação, articulados aos grandes projetos de investimento (GPI).

3 Contudo, com a crise desencadeada a partir de 2014 no país, muitos desses projetos foram abandonados e/ou modificados, sobretudo, após a mudança da conjuntura política nacional após o golpe em 2016. Algumas dessas infraestruturas, que se constituem como importante investimento nas bases logísticas no estado, permanecem de grande interesse ao capital, mas como deixam de receber recursos que eram destinados pelos governos da União, entram nos planos do Estado para serem privatizadas ou concedidas à administração privada. Isto acontece em um cenário em que a entrega desses ativos ocorrem sem muitas restrições ou condicionantes para a ampliação dos serviços prestados.

4 Nesse contexto, eixos viários importantes como a BR101, BR116, BR493 (que compõe a rodovia conhecida como Arco Metropolitano1), estão em processo de licitação de novos trechos e re-licitação das concessões já existentes, sem que um plano de integração do território seja, de fato, produzido para articular os grandes eixos viários à interesses locais e regionais, para fortalecer a base logística nas regiões e dinamizar os encadeamentos produtivos no estado.

5 Sendo assim, o estudo realizado tem por base teórica a compreensão de que as infraestruturas de circulação, considerada aqui como redes técnicas, são instrumentos de modernização ${ }^{2}$ (CASTILHO, 2018), logo, elas permitem o fluxo de comunicação, informação, energia, cargas, pessoas, insumos entre outros, proporcionando uma lógica espacial de produção.

Desse modo, este trabalho ${ }^{3}$ pretende uma investigação das mudanças ocorridas no leste metropolitano do Rio de Janeiro (LMRJ) após a construção de redes técnicas direcionadas a uma nova espacialização das atividades econômicas, que vem induzindo na formação de novos arranjos espaciais, por ocasião da construção de grandes projetos de investimento. A presente pesquisa é parte do estudo para dissertação de mestrado, cujo objetivo é compreender a reestruturação metropolitana e as potencialidades das redes técnicas para uma integração regional entre o leste metropolitano e o norte fluminense.

7 Neste artigo buscou-se inicialmente trazer o cenário logístico e rodoviário metropolitano fluminense, com destaque ao eixo rodoviário Rio - Governador Valadares/MG e o Arco Metropolitano que estão para serem entregues à iniciativa privada para as próximas três décadas. Posteriormente, é exposto quais as mudanças territoriais em curso no LMRJ e as potencialidades das redes técnicas que proporcionam a localização estratégica de integração com diferentes regiões do estado. No final, são levantadas as discussões acerca do que poderá estar em jogo com a entrega desses ativos e quais os entraves que permanecem comprometendo a estrutura logística e o encadeamento produtivo no LMRJ.

\section{As redes técnicas e a integração logística do território}

8 No estado do Rio de Janeiro, a construção de novas bases logísticas para comportar os Grandes projetos de investimento (GPI's), proporcionou a formação de novas centralidades na periferia metropolitana fluminense. Ou seja, essas centralidades 
secundárias se apresentam pela desconcentração de investimentos e infraestruturas que antes eram predominantes ao núcleo urbano da cidade do Rio de Janeiro. Desse modo, após as mudanças territoriais na periferia metropolitana do Rio de Janeiro, houve uma multipolarização produtiva e logística, trazendo novas padrões de circulação, de investimento, especulação imobiliária etc. (OLIVEIRA e CANDIDO, 2018). Essas centralidades baseiam-se no circuito produtivo do petróleo e gás no estado, como também no escoamento de mercadorias entre os estados de Minas Gerais, São Paulo e Espírito Santo.

9 Dessa maneira, a construção e duplicação de rodovias como o Arco Metropolitano (BR 493), BR 116 e BR 101 tem como objetivo proporcionar melhorias de circulação na periferia da região metropolitana que antes não ofereciam vantagens locacionais e não possuíam infraestrutura logística adequada. A circulação se torna possível com investimento de diferentes redes técnicas, como rodovias, redes de eletricidade, gasodutos, rede de fibra óptica, entre outros, que são cruciais para o processo de integração de regiões estratégicas. Portanto, conforme Gottman:

"A circulação é naturalmente criadora de mudanças na ordem estabelecida do espaço: ela consiste em se deslocar. Na ordem política, ela desloca os homens, as armas e as ideias; na ordem econômica, ela desloca as mercadorias, as técnicas, os capitais e os mercados; na ordem cultural, ela desloca as ideias, mistura os homens. ( GOTTMAN apud ARROYO, 2015, p.37)

10 Portanto, a circulação tem papel importante em diferentes esferas que resultam em grandes mudanças territoriais e sociais. Por essa questão, a reestruturação espacial desencadeada pela expansão das cadeias produtivas de petróleo e gás no estado fluminense, estimulou a expansão de redes técnicas que vem redefinindo centralidades. Logo, a incorporação de territórios (nesse caso os limites territoriais conforme delimitação municipal) ligados por redes de circulação após a inserção dos grandes projetos de investimento (GPI's), permite um movimento expansionista causado pelas redes técnicas (RUFINO,2019); que influi na metropolização do espaço (LENCIONI, 2017) como processo espacial e a integração territorial.

11 Por redes técnicas compreende-se que são produções humanas no espaço geográfico, proporcionando fluidez material e imaterial, aumentando a capacidade produtiva e consequentemente a espacialidade da produção (SANTOS,1996; RAFFESTIN,1993). Portanto, conforme Raffestin (1993), "a circulação é a imagem do poder", e por isso as redes técnicas estão sempre em disputa e gerando conflito. Dessa maneira, no decorrer da construção das redes em diferentes momentos da história, evidencia a manutenção e expansão de uso do território.

12 No caso do território metropolitano fluminense, o Arco Metropolitano possui uma grande importância econômica, pois viabiliza uma interligação com diferentes rodovias que se estendem a diferentes regiões do país. A extensão do Arco Metropolitano integra parte do circuito espacial da produção e da cadeia produtiva do petróleo e gás do Rio de Janeiro (OLIVEIRA E PESSANHA, 2019), interligando grandes empreendimentos como o Polo Gáslub Itaboraí (ex-Comperj), a REDUC, ao Pólo gás químico de Duque de Caxias, ao Complexo industrial de Santa Cruz, PLANGÁS, além de influenciar no surgimento de atividades econômicas e novos arranjos produtivos locais (OLIVEIRA,2020). Desse modo, as infraestruturas presentes nos eixos viários dos planos de concessão no Rio de Janeiro, apresentam a circulação aparente do poder, portanto, essas redes técnicas promovem um tipo de circulação visível dos fluxos, enquanto camufla "quem 
comanda", ou seja, é necessário conhecer não só as redes, mas as ações e a lógica dos atores (DIAS, 2007). Como resultado, o que vemos com as infraestruturas é só a parte aparente do fluxo de poder, sustentado pelo dualismo entre privilégio e restrição.

Dessa forma, ao analisarmos as redes, necessitamos compreender "a política, os processos e as ações que lhe dão funcionalidade"(CASTILHO,2019), para não nos restringirmos ao visível, mas também aquilo que não quer ser visto (RAFFESTIN,1993). Nessa mesma perspectiva, Milton Santos (2009[1996]) ao afirmar que "as redes também são sociais e políticas", não só integram pontos e linhas, lugares e regiões, mas expõe as estratégias de dominação e uso do território que, na maior parte das vezes, ocorrem pelos setores dominantes da economia e elites políticas. Nestas duas dimensões das redes, o social e o político, o Estado é o detentor dos critérios e normas na utilização das redes, acaba por regular a favor dos que detém o poder.

Especificamente, para efeito deste estudo, consideramos o projeto de concessão em andamento, a Rio - Governador Valadares, totaliza 722,3 quilômetros de rodovias federais. A proposta é de ampliação das concessões anteriores em um trecho já concedido e expansão da malha rodoviária, por um novo período de 30 anos. 0 novo projeto em licitação, que já foi submetido à audiência pública ${ }^{5}$, em dezembro de 2020 , na ANTT, expande o projeto de concessão incorporando os investimentos realizados na construção do trecho do Arco Metropolitano, realizado com recursos públicos.

Esse sistema rodoviário proposto para concessão possui grande importância por estabelecer vias de circulação estratégica com potencial para a localização de investimentos industriais ao longo da rodovia, sobretudo, nos municípios da região metropolitana do Rio de Janeiro. A partir dessa perspectiva, as mudanças territoriais que vêm ocorrendo na região metropolitana do Rio de Janeiro decorrente dos GPI's e expansão dessas redes logísticas, têm apresentado aumento da circulação do fluxo de cargas, de capital e mão de obra. Isso resulta na integração logística relevante que viabilizará, após a duplicação do último trecho do Arco Metropolitano, entre Magé e Itaboraí, não só o eixo litorâneo de integração nacional do Nordeste e do Sudeste, do Sul da Bahia e Espírito Santo à São Paulo, como se constituirá uma via de dinamização da economia local, integrando o território em termos de bases logística de Maricá a Itaguaí. Como também, proporciona maior integração com o estado de Minas Gerais, e outras regiões no estado, como o Norte e Noroeste Fluminense, pelo acesso que a BR 493 (leste) tem com a BR $101 \mathrm{Sul}$, assim como com a estrada de acesso ao Comperj, e a estrada UHOS (que interliga o distrito industrial de Guaxindiba ao porto de São Gonçalo, no bairro de Itaóca) - (CANDIDO,2019). O entroncamento dessas rodovias possui grande potencial de tráfego, devido ao aumento do escoamento de cargas resultantes da nova dinamização na periferia metropolitana fluminense com os projetos de grande envergadura como apresentado anteriormente.

Importantes referências encontradas nos trabalhos de Álvaro Ferreira (2015) e Sandra Lencioni (2017), e outros, apresentam contribuições para compreender essa dinâmica metropolitana em curso no estado do Rio de Janeiro, advinda de uma dinamização econômica desencadeada principalmente por eixos de ligação entre regiões com intensa integração produtiva. Nesse caso, a inserção de novas infraestruturas redefine as relações entre sociedade e território, pois as mudanças que esses objetos ocasionam na organização do espaço trazem novas funcionalidades ao território. Nesse caso, a construção de GPI's e a finalização do Arco Metropolitano expande a periferia da malha metropolitana fluminense, reorganizando os intensos fluxos que antes se concentravam 
à metrópole, como a Avenida Brasil e a Ponte Rio-Niterói (BR 101). Ferreira et al (2015:23) afirma que a metropolização tem como principal marca a intensidade de fluxos que se adensam conforme o aumento da integração, que "corresponderia a uma organização espacial integrada à lógica da acumulação capitalista(...)".

17 Portanto, consideramos que a integração logística que tem sido fortalecida no LMRJ $^{6}$ a partir do ano de 2006, com o anúncio da exploração do Pré-sal e do Comperj, constitui um processo socioespacial contemporâneo que é a metropolização (LENCIONI,2017), que está intimamente ligado à dinâmica metropolitana com a reestruturação produtiva (HARVEY, 2014[1989]).

Esses novos investimentos promoveram transformações logísticas que induziram a modernização das bases para os fluxos entre regiões do Rio de Janeiro, assim como com outros estados (SP, MG e ES). Logo, essas mudanças territoriais ocorreram relativas ao uso estratégico do território, que não viam investimentos desse porte deste a construção da Linha Vermelha, rodovia de ligação do centro da cidade do Rio de Janeiro, facilitando o acesso ao Aeroporto do Galeão e às rodovias BR-040 e BR-116 sul.

19 Tais investimentos, que entre 2014 e o início do segundo semestre de 2021, foram revertidos em um quadro de estagnação em termos de investimentos em logísticas rodoviárias no estado, só retomam ao diálogo na esfera política e empresarial para a entrega desses ativos públicos às concessionárias. Logo, o que está em questão é que "os serviços transferidos à iniciativa privada perdem seu caráter público"(SILVEIRA,2019) e estratégico.

\section{Relicitação e expansão de concessões: o projeto rio- Governador Valadares}

\section{Eixo rodoviário fluminense em mãos de um projeto de concessão em massa.}

20 Os dois principais eixos rodoviários do estado do Rio de Janeiro são a BR-116 e a BR 101, que integram o Rio de Janeiro com importantes cidades como São Paulo, cidades da região Sul e do Nordeste. A BR 116 tem como característica ser totalmente pavimentada, desde Fortaleza, no Ceará, até Jaguarão, no Rio Grande do Sul, possuindo alguns trechos sob concessão. Essa rodovia tem diferentes denominações regionais por todo país, e especificamente no estado do Rio de Janeiro, definimos em 2 segmentos.

21 O primeiro segmento, com $402 \mathrm{~km}$, é denominado Rodovia Presidente Dutra. Este trecho está sob concessão há 25 anos com a concessionária Rodovia Presidente Dutra S/ A - "Nova Dutra", do Grupo CCR, e faz integração entre as cidades do Rio de Janeiro e São Paulo, as duas maiores regiões metropolitanas do país. Logo, esse trecho é um dos mais movimentados do país, e recebe em média 722 mil viagens por dia (incluindo as viagens de curta e longa distância). A concessão da rodovia Presidente Dutra pela CCR, inicia no km 163 da BR 116, no trevo das Margaridas no entroncamento com a Avenida Brasil (BR 101), na cidade do Rio de Janeiro até o km 231 no entroncamento com a BR 395 e SP 015, na marginal Tietê, em São Paulo.

O grupo CCR possui $3.644 .502 \mathrm{~km}$ de concessão por todo o país, é o único acionista da Nova Dutra. Esse trecho é um dos mais rentáveis do país, e os estudos de relicitação ${ }^{7}$ já possuíam empresas interessadas, dentre elas as espanholas Arteris, Sacyr, e 
Ecorodovias ${ }^{8}$. Contudo, no processo de relicitação, ocorrida no mês de outubro de 2021, apenas CCR e Ecorodovias concorreram, com a própria CCR tendo sido vitoriosa, com a oferta de um desconto de $15,36 \%$ no valor do pedágio.

Imagem 1: Eixos Rodoviários Federais em concessão e relicitação no estado do Rio de Janeiro

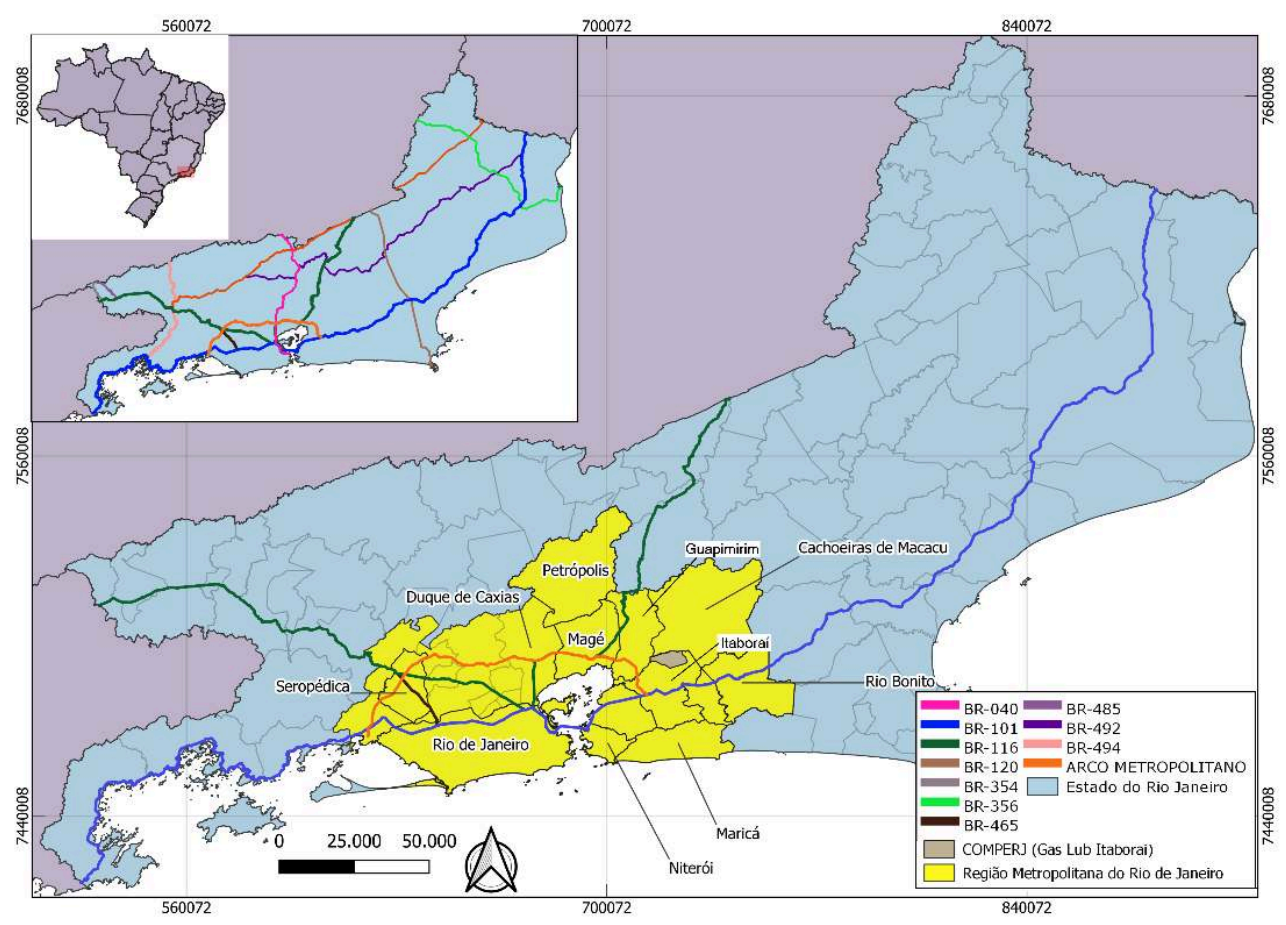

Organização: CANDIDO, D'Jeanine, 2021. Fonte: Base de dados do IBGE (2020) e MINFRA (2010).

O segundo segmento, que será o trecho de destaque nesse trabalho, possui $142,5 \mathrm{~km}$ e é nomeado Rio-Teresópolis ${ }^{9}$ ou Rio-Bahia, iniciando seu trajeto no entroncamento com a BR 493, o atual Arco Metropolitano, em Santa Guilhermina, em Magé até o entroncamento com a BR 393, em Além Paraíba, em Minas Gerais, seguindo para o estado de Minas Gerais e depois para a Bahia. Essa rodovia, sobrepondo uma parte da BR $493^{10}$, a partir de Duque de Caxias no entroncamento com a BR 040, está atualmente sob concessão da $\mathrm{CRT}^{11}$ (Concessionária Rio-Teresópolis S/A), um consórcio de empresas possuindo como acionistas a INVEPAR, empresa atuante em mobilidade urbana, rodovias e aeroportos com 9 concessões. Também atua como acionista, no VLT carioca, Via Rio, e é controladora da Linha Amarela e CLN, entre outros. Outras acionistas são, a Carioca Christian Nielsen Concessões S/A, Queiroz Galvão participações e concessões S/A, Queiroz Galvão Construtora, CRT Fundo de investimento, entre outros com menor participação. 


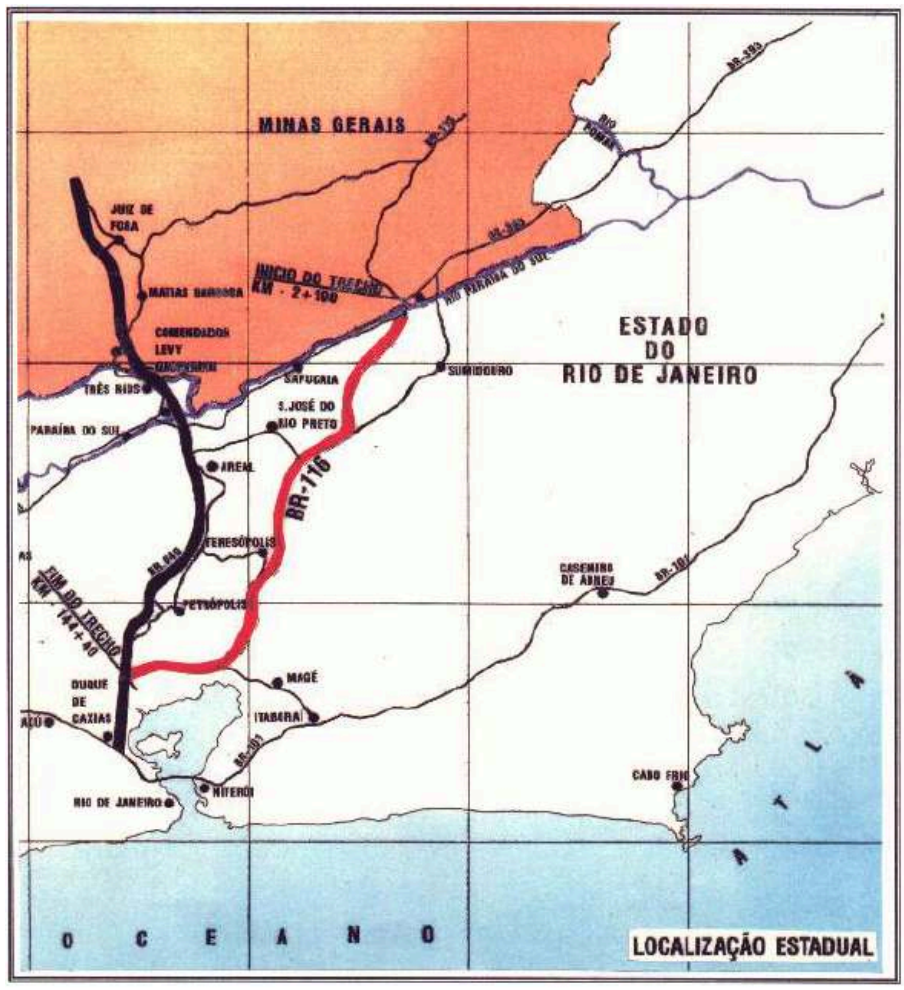

Fonte: ANTT. PER - BR116/RJ, 2010

A concessionária da rodovia Rio-Teresópolis possui 3 praças de pedágio ${ }^{12}$, todas nos limites da cidade de Magé. O valor mais alto é cobrado na praça principal Engenheiro Pierre Berman, em Bongaba com tarifa de $\mathrm{R} \$ 18,80^{13}$ nos dois sentidos para carros de passeio. As localizações das praças de pedágio da concessionária já são contestadas pela população de Magé e Guapimirim desde o início da concessão, pois as tarifas são fixas e não são cobradas pela distância percorrida, o que tem ocasionado insatisfação, prejudicando as pequenas viagens nessas cidades.

Com o início das atividades do projeto de concessões, a população de Guapimirim e Magé teme o aumento da cobrança dos pedágios e/ou a criação de mais praças, isolando ainda mais as cidades, uma vez que o novo traçado será aumentado. Por essa questão, esses municípios não têm interesse em obterem praças de pedágios em seus limites administrativos.

Como exemplo, em Guapimirim que não possui praça de pedágio, mas já sente influência dos existentes na cidade vizinha (Magé), poderá ter duas praças de pedágio. Uma decorrente de uma concessão na RJ-122 ${ }^{14}$, que interliga Guapimirim à Cachoeira de Macacu e outra pela concessão do Projeto Rio-Valadares, no Km 9,7 da BR 493. Em Magé, já existem 3 praças de pedágio ( $\mathrm{km} \mathrm{114,} \mathrm{km} 122, \mathrm{Km} 133,5)$ da concessionária CRT $\mathrm{S} / \mathrm{A}$. Em decorrência da finalização do contrato de concessão e os trâmites para o início do novo projeto, a CRT ganhou a prorrogação da concessão por mais 18 meses, o que gerou insatisfação da prefeitura de Magé, ocasionando em uma ação civil pública ${ }^{15}$ contra a ANTT, DNIT, CRT e AGU, para o cancelamento da cobrança e pedágio da praça Eng. Berman. 
27 Em meio aos desacordos entre o interesse político, comercial local e social, algumas prefeituras buscam tomar medidas, como a criação de uma rota alternativa.

Os dois segmentos citados da BR 116 são trechos em concessão desde 1995, e ambos estão em processo de novas negociações. A nova concessão resultante deste novo projeto tem como meta a incorporação de novos trechos, bem como um contrato por mais 30 anos. Os novos projetos de concessão fazem parte do Programa de Parcerias de Investimentos (PPI), criado em $2016^{16}$ e nomeado como "Projeto Crescer", durante o governo Michel Temer (2016-2018), tem como principal objetivo aumentar as desestatizações e contratos de parcerias com empresas privadas nos ativos públicos. 0 PPI iniciou com o objetivo de incluir projetos do Programa de Aceleração e Crescimento (PAC) e do Programa de Investimento e Logística (PIL) dos governos anteriores ${ }^{17}$.

29 A partir do governo Bolsonaro em 2019, foi criado uma agenda de privatização, relicitação e concessão incluindo os projetos de infraestrutura dos governos anteriores. Logo, o plano tem como objetivo fazer 8 privatizações estatais ${ }^{18} \mathrm{e}$ a concessão de mais de 100 ativos à iniciativa privada até o final do mandato em 2022. Entre 2019 e 2021, foram leiloados 41 ativos públicos. Somente em abril de 2021, durante a Infraweek, nome dado a semana de leilões, o governo federal concedeu à iniciativa privada 29 ativos de infraestrutura ${ }^{19}$ com validade de 30 anos $^{20}$. (MINFRA,2021)

Conforme o órgão responsável pelos projetos de concessões e desestatizações, o Programa de Parceria de Investimentos ${ }^{21}$, 159 projetos estão em andamento. Já são 5 concessões rodoviárias concluídas e 13 em andamento.

\section{O projeto do sistema rodoviário Rio-Governador Valadares}

O projeto do sistema rodoviário da Rio-Valadares faz parte do planejamento logístico do PNL 2025 e PNL 2035, em que o MINFRA (Ministério da Infraestrutura) faz uso para o planejamento de ações dos projetos de obras públicas, e programas de concessões e relicitações rodoviárias e ferroviárias. Assim como outras rodovias estratégicas no país, o sistema rodoviário Rio-Valadares ${ }^{22}$ faz parte do planejamento de ampliação e de relicitação.

O projeto foi elaborado pela empresa pública EPL (Empresa de planejamento e logística), que é um órgão responsável pelo estudo de projetos voltados à circulação e transporte de cargas e passageiros, e enviado ao MINFRA e a ANTT no $2^{\circ}$ semestre de 2020.

O sistema rodoviário Rio de Janeiro - Governador Valadares, nomeado "lote 4" é formado pelas rodovias BR-116/RJ (191 km²3), BR-116/MG (410 km), BR-465/RJ (22,5 km) e BR-493/RJ (100 km), totalizando $722,5 \mathrm{~km}^{24}$. O projeto faz parte do Programa de Parcerias de Investimentos (PPI) e do Programa Nacional de Desestatização (PND) ${ }^{25}$, e prevê o leilão para 2022 e estabelece uma concessão por 30 anos para esta e demais rodovias. A concessão Rio-Valadares é um dos 36 projetos entre portos, rodovias, ferrovias e aeroportos que o Plano Nacional de logística EPL estruturou no ano de 2020. 
Imagem 3: Sistema rodoviário Rio-Governador Valadares(BR-116 RJ/MG, BR-116 RMRJ, BR-493)

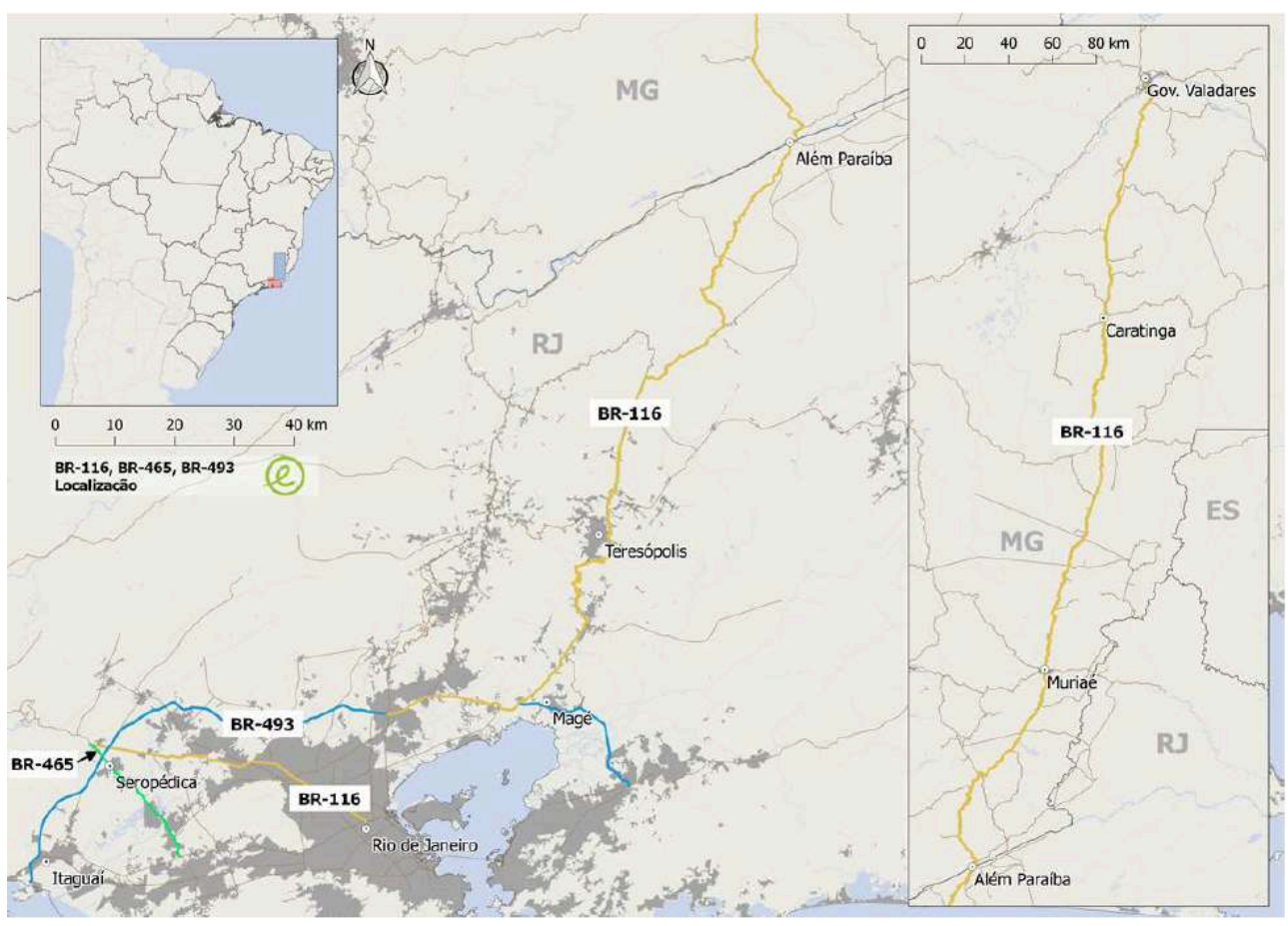

Fonte: ANTT. PER - BR-116/RJ/MG, BR-465/RJ e BR-493/RJ. 2020

Para melhor compreensão do mapa, queremos identificar trecho por trecho que aparece na figura. $O$ primeiro trecho equivale à BR.493 (em azul no canto esquerdo da figura e um pequeno trecho de ligação entre Magé e Itaboraí), ainda sem concessão, é o que liga o Porto de Itaguaí ao entroncamento com a BR 040, e depois, Magé à Manilha no entroncamento com a BR.101 norte. A partir daí segue os dois trechos seguintes, da BR-116 (cor amarela), a primeira até o município de Além Paraíba, que já possui concessão e são pedagiadas. Por fim, o trecho destacado na parte direita da figura, que vai de Além Paraíba à Governador Valadares. Atualmente, essas rodovias estão com diferentes administrações, e o projeto visa aglutinar em um único sistema rodoviário. Em especial, o Arco Metropolitano que foi um projeto do PAC e foi construído durante os anos 2007-2014, com objetivo de integração regional para o fluxo de cargas e produção. A construção do Arco metropolitano foi dividida em 4 segmentos, mas somente o trecho entre Manilha e Santa Guilhermina/Magé não foi duplicado. Desde então, o trecho permanece sob administração do DNIT. Contudo, com interesse em entregar a rodovia à concessão, desde a sua inauguração, o Arco Metropolitano tem sido abandonado. Logo, esses ativos públicos acabam por ser desvalorizados e ganham a adesão da opinião pública para uma concessão extremamente vantajosa ao capital. 
Tabela 1: Extensão do projeto de rodovias da Rio-Valadares

\begin{tabular}{|c|c|c|c|c|c|c|c|}
\hline \multirow{2}{*}{ Rodovia } & \multirow{2}{*}{$\begin{array}{c}\text { Atual } \\
\text { Administração }\end{array}$} & \multirow{2}{*}{ Nomeação } & \multicolumn{4}{|c|}{ Segmento } & \multirow{2}{*}{$\begin{array}{c}\text { Extensão } \\
\text { do } \\
\text { projeto(2) }\end{array}$} \\
\hline & & & Início & $\mathrm{km}_{(1)}$ & Fim & $\mathrm{km}_{(1)}$ & \\
\hline BR 493 LMRJ & DNIT & \multirow{2}{*}{ Arco Metropolitano } & Itaborai/RJ & 0 & Magé/RJ & 26 & \multirow{2}{*}{$99,8 \mathrm{Km}$} \\
\hline BR 493 & DNIT & & Duque de Caxias/RJ & 48,1 & Itaguai/RJ & 123,7 & \\
\hline BR 465 & DNIT & "Antiga" RJ-SP & Seropédica/RJ & 0 & Rio de Janeiro/RJ & 22,8 & $22,5 \mathrm{~km}$ \\
\hline BR 116/MG & DNIT & $\begin{array}{l}\text { Rio-Bahia ou Rod. } \\
\text { Santos Dumont }\end{array}$ & Além Paraíba/MG & 408,5 & $\begin{array}{c}\text { Governador } \\
\text { Valadares/MG }\end{array}$ & 818,1 & $407 \mathrm{~km}$ \\
\hline BR 116/RJ & CRT & Rio - Teresópolis & Sapucaia/RJ & 2,1 & Magé/RJ & 146,3 & $146 \mathrm{~km}$ \\
\hline BR 116/RMRJ & $\begin{array}{l}\text { CCR Nova } \\
\text { Dutra }\end{array}$ & Rod. Pres Dutra & Rio de Janeiro/RJ & 168,1 & Seropédica/RJ & 214,7 & $46,6 \mathrm{~km}$ \\
\hline \multicolumn{7}{|l|}{ Total } & $722,3 \mathrm{~km}$ \\
\hline
\end{tabular}

* Entre Duque de Caxias e Magé há a sobreposição da BR 116 com o Arco Metropolitano

Fonte: CANDIDO, D'Jeanine, 2021. Com base em dados da SNV(1)(2019) e Estudo de viabilidade técnica, EPL.

No contrato é estabelecido a duplicação de $309,52 \mathrm{~km}$ pela concessionária, em sua maioria no estado de Minas Gerais, nos 9 primeiros anos de concessão. A ampliação do projeto tem como premissa possibilitar ao setor privado alta rentabilidade proporcionada por trechos estratégicos com alto fluxo de tráfego.

Para isso, a concessão resultaria na construção de 11 praças de pedágio bidirecionais substituindo as já existentes, sendo 5 na RMRJ. A distribuição inclui 3 praças de pedágio bidirecionais na BR 116/RJ, sendo uma em Magé e duas em Seropédica, e mais 2 praças de pedágio no Arco Metropolitano, sendo uma em Itaboraí/Guapimirim e outra em Itaguaí.

Tabela 2: Distribuição das praças de pedágio do projeto Rio-Governador Valadares.

\begin{tabular}{|c|c|c|c|c|c|}
\hline & Rodovia & Km & Praça de Pedágio & UF & Sentido da cobrança \\
\hline 1 & BR-116 & 207,100 & Viúva Graça & RJ & Bi-direcional \\
\hline 2 & BR-116 & 207,100 & Viúva Graça (B) & RJ & Bi-direcional \\
\hline 3 & BR-116 & 127,000 & Magé & RJ & Bi-direcional \\
\hline 4 & BR-493 & 9,700 & Itaboraí & RJ & Bi-direcional \\
\hline 5 & BR-493 & 112,900 & Itaguaí & RJ & Bi-direcional \\
\hline 6 & BR-116 & 789,900 & Leopoldina & MG & Bi-direcional \\
\hline 7 & BR-116 & 724,600 & Bom Jesus da Cachoeira & MG & Bi-direcional \\
\hline 8 & BR-116 & 670,700 & Miradouro & MG & Bi-direcional \\
\hline 9 & BR-116 & 615,900 & Orizânia & MG & Bi-direcional \\
\hline 10 & BR-116 & 555,400 & Santa Bárbara do Leste & MG & Bi-direcional \\
\hline 11 & BR-116 & 487,500 & Inhapim & MG & Bi-direcional \\
\hline 12 & BR-116 & 433,200 & Governador Valadares & MG & Bi-direcional \\
\hline
\end{tabular}

Fonte: ANTT, 2020. Disponível em: https://www.gov.br/antt/pt-br/assuntos/ultimas-noticias/antt-abreap-sobre-nova-concessao-br-176-rj-mg-e-br-465-493-rj

37 A concessão terá como justificativa para a inclusão das novas praças de pedágio ${ }^{26}$, um leilão com base na tarifa reduzida, e no desconto para usuário frequente (DUF), que se refere ao sistema de cobrança eletrônico para usuários de algumas categorias de veículos que trafegam no mesmo sentido e mesma praça de pedágio em um período de um mês ${ }^{27}$. Esse critério de sistema de livre passagem, que é o pagamento proporcional pelo uso da rodovia, conhecida como free flow ${ }^{28}$, vem como meio de melhor adesão do 
apoio popular, como também como contrapartida a mudança no modelo de outorga das concessões a partir de 2016 (SILVEIRA, 2019).

\section{Finalização do arco metropolitano chega com novas expectativas}

O Arco Metropolitano possui importância de integração de polos estratégicos como as infraestruturas do antigo projeto do Comperj (atual Polo Gaslub), a Reduc, ao Porto de Itaguaí e seu distrito industrial. Além disso, possibilita a conexão com 5 grandes eixos rodoviários federais de acesso do Rio de Janeiro, como Minas Gerais (BR-040), Bahia (BR. 116 Norte), São Paulo (BR.116 Sul), Santos (BR.101 Sul) e Espírito Santo (BR.101 Norte), dentre outras interseções com outras vias locais. Sua localização possibilita o menor custo logístico, evitando outras vias já saturadas pelo tráfego na capital fluminense e as restrições de cargas em horários específicos na Ponte Rio-Niterói (BR 101). A finalização do trajeto traz uma rota preferencial na trafegabilidade de cargas, além de integrar vários municípios periféricos da RMRJ com alto contingente de mão de obra e novos espaços industriais, consolidando sua utilização logístico-industrial, integrando diretamente eixos multimodais na RMRJ, como Portos e píeres ${ }^{29}$, heliportos, aeroportos, ferrovia (projeto da construção da EF-118 - interligando Anchieta, ES, à Queimados, RJ)

O trecho Magé-Manilha, já recebe intenso fluxo de cargas vindo do oeste metropolitano e São Paulo em direção ao leste metropolitano e ao norte do estado. A finalização da duplicação já é uma demanda antiga dos usuários da rodovia, que a consideram perigosa, pois há grande tráfego de caminhões em uma pista dupla, em sua maioria, sem acostamento, sem iluminação, sinalização, policiamento e com má conservação, como pode ser observado nas imagens 4,5 e 6 .

Imagem 4. Trecho da rodovia BR.493, entre Magé e Manilha, em Itaboraí.

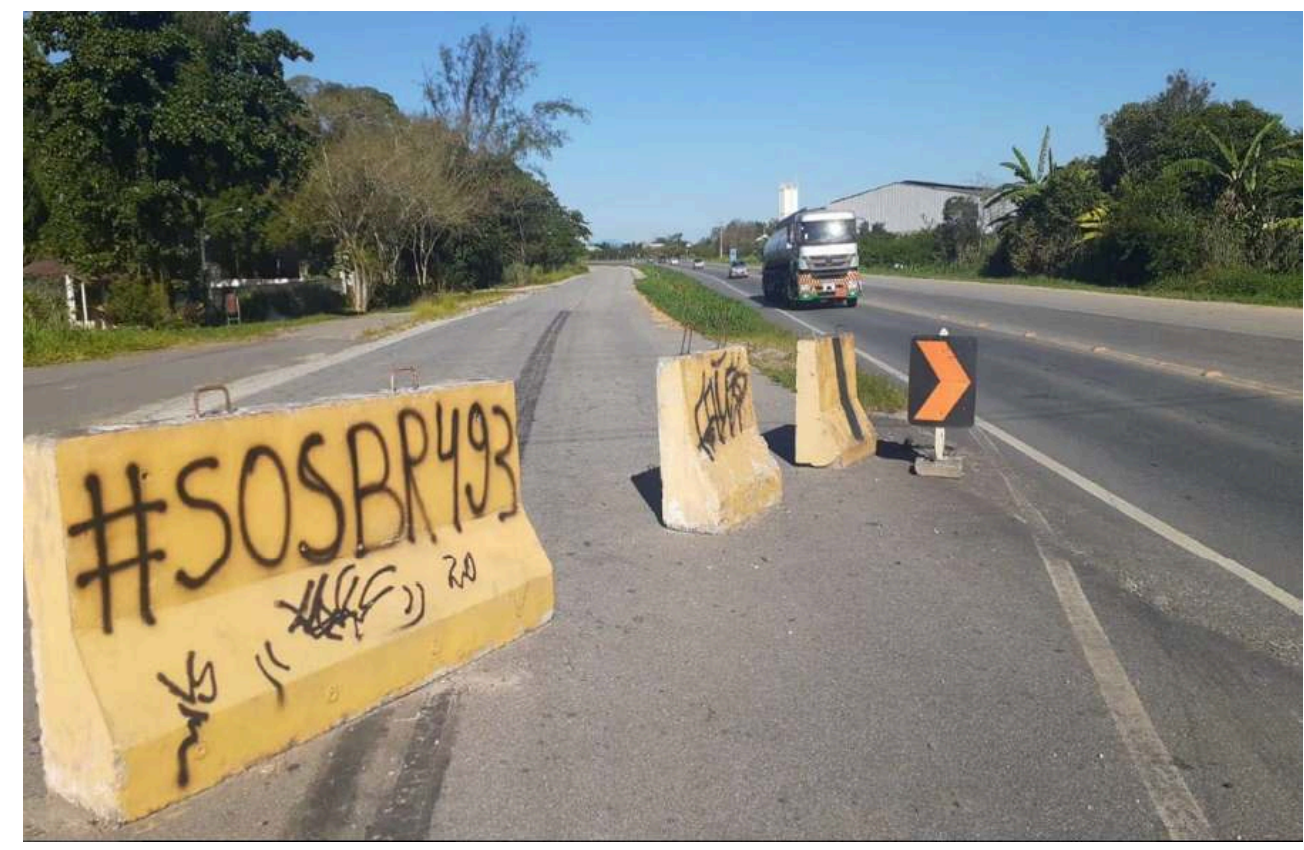

Fonte: CANDIDO, D'Jeanine. (abr. 2021) 
Imagem 5. Trecho da rodovia BR.493, entre Magé e Manilha, em Itaboraí.

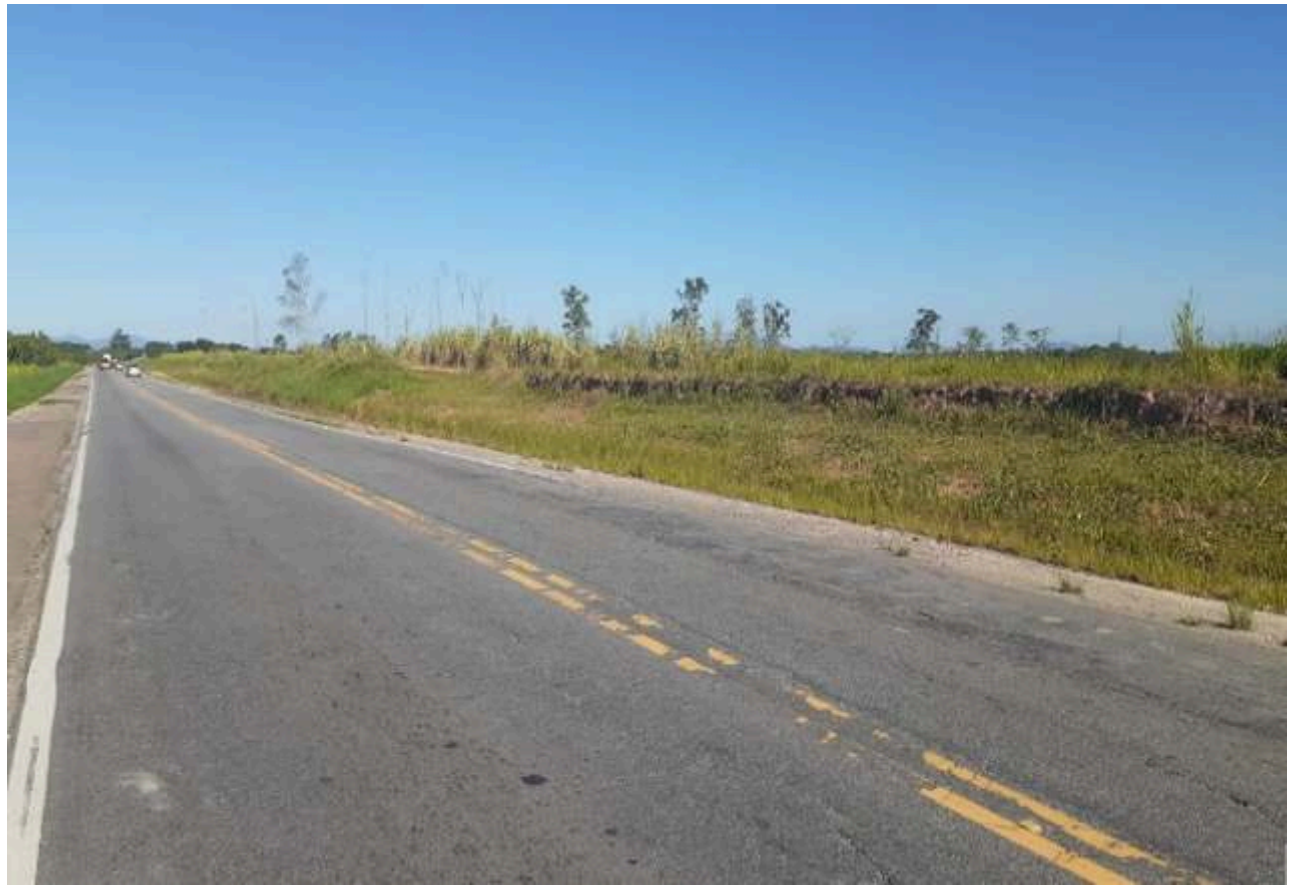

Fonte: CANDIDO, D'Jeanine. (abr. 2021)

Também merece destaque também que as condições de mobilidade da estrada não comportam o aumento do fluxo, crescente no decorrer dos anos, o que resulta em extensos quilômetros de congestionamento de caminhões no trevo de Manilha entroncamento da BR 493 com a BR 101, registrado na imagem a seguir. Se tratando de duas rodovias federais duplicadas, seu potencial ainda estará muito limitado caso não se considere uma reestruturação dos acessos por meio de alargamento de viadutos ou alças de retorno no cruzamento em Manilha, Itaboraí. O cruzamento recebe todo o fluxo de veículos de carros de passeio que cruzam a BR.101 deste Ponte Rio-Niterói em direção à região da Baixada Litorânea do estado. Passar por esse entroncamento em veículos leves, em direção à Cabo Frio, por exemplo, pode significar sofrer engarrafamentos de 2 a 6 horas, dependendo do horário ou proximidade de dias festivos ou fins de semana. 
Imagem 7. Entroncamento da BR 101 Norte com o Arco Metropolitano (BR 493) e RJ 104 - Trevo de Manilha.

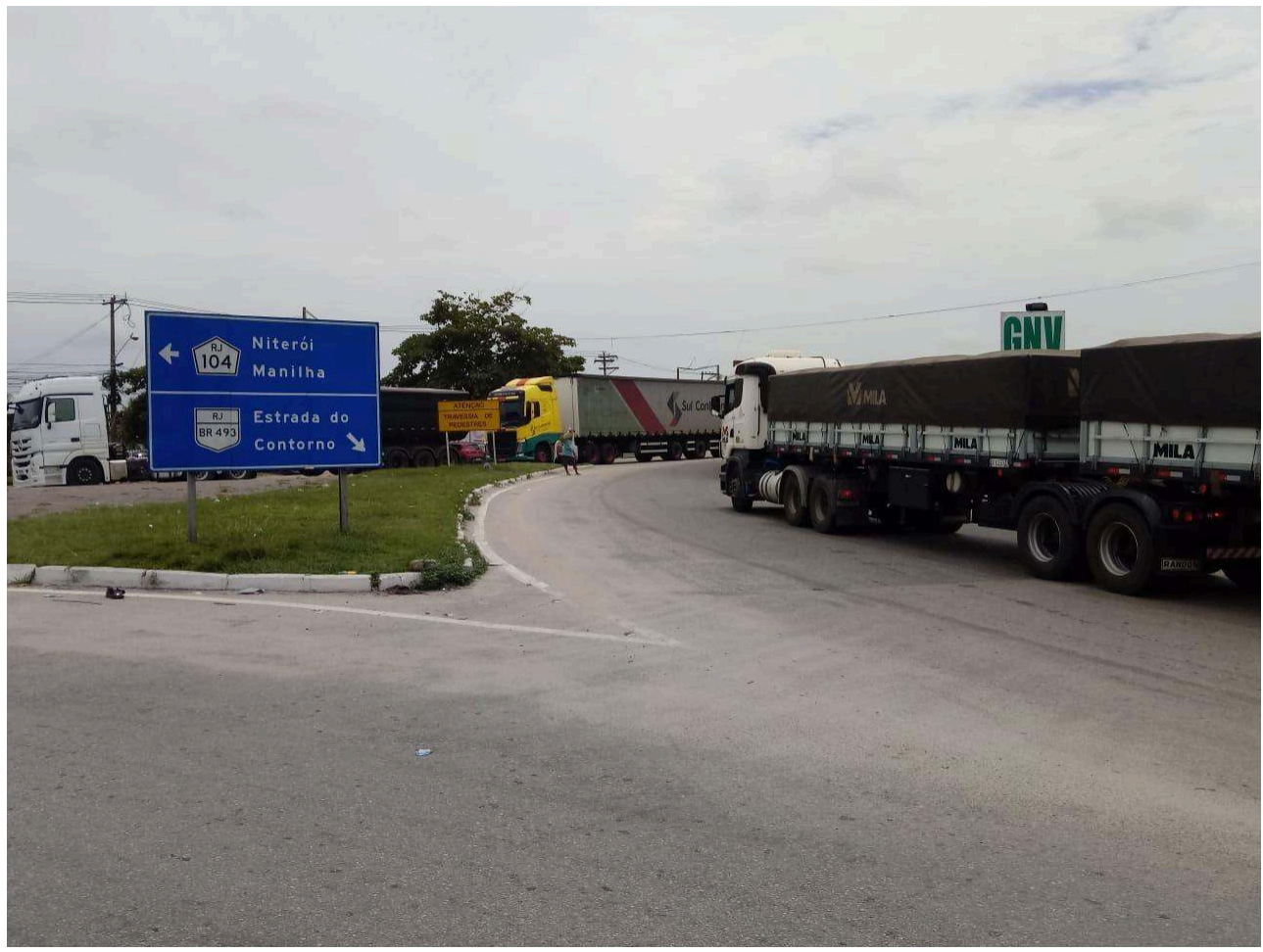

Fonte: CANDIDO, D'Jeanine. (out. 2021)

A concessão do Arco Metropolitano já era indicada em toda a sua extensão (Itaguaí a Itaboraí) (SETRANS,2016). Com a confirmação o prosseguimento do projeto RioGovernador Valadares, as obras do trecho Manilha-Magé foram retomadas ${ }^{30}$ no $2^{\circ}$ semestre de 2021, depois de 6 anos paralisadas.

Durante esse período, ficaram abandonados materiais de construção nas margens da via, deixados ferros expostos, entulhos etc. Logo, resultou no acúmulo de água parada, principalmente nas passagens inferiores (imagem 7), com proliferação de insetos, bem como a má iluminação que dificultavam a travessia dos moradores da região, por não haver passarelas suficientes no trajeto. A BR-493 Leste atravessa bairros como Gebara, Itambi, Jardim Santo Amaro entre outros que compartilham de falta de políticas públicas voltadas para as melhorias da região. 
Imagem 7. Obras inacabadas, entre Santa Guilhermina, Magé e Manilha, Itaboraí

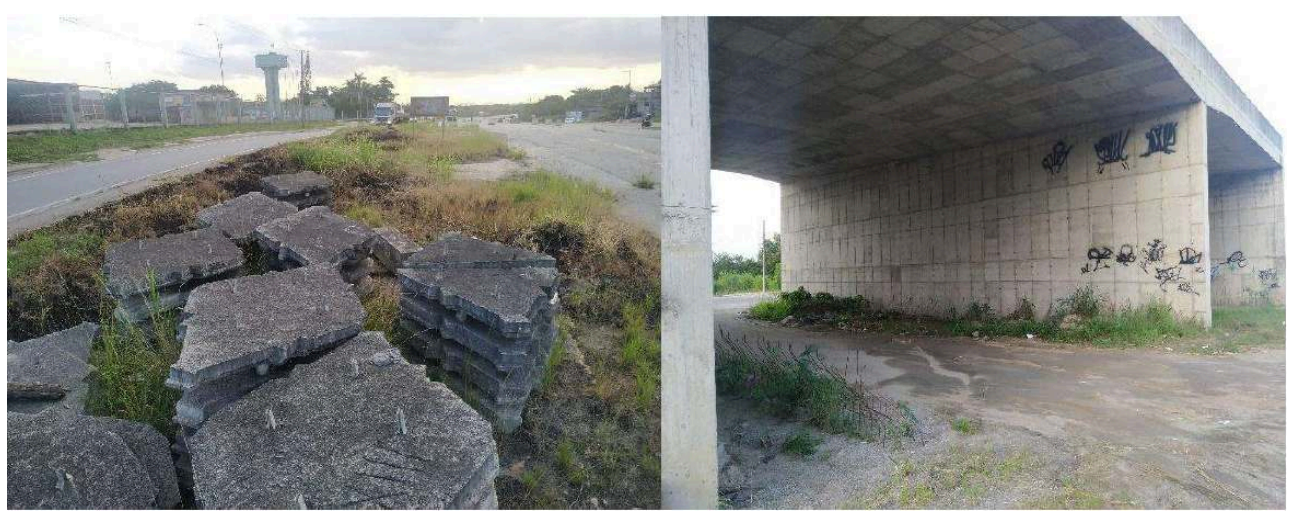

Fonte: AQUINO, Sara. (abr,2021)

A seguir, podemos observar na imagem 8 , um conjunto habitacional abandonado que foi projetado ao lado da rodovia destinado a abrigar alguns moradores que seriam removidos de áreas de desapropriação para a duplicação da estrada e que foram incluídas nos projetos do PAC social. A construção tinha também o objetivo de distribuição de apartamentos populares para a Comunidade da Bacia, em Itambi. Esta comunidade tem como atividade principal de catadores de Caranguejo na região de manguezal na APA de Guapimirim. Na época, o conjunto habitacional previa receber seus primeiros moradores em 2010. Hoje, segundo a própria população local, o conjunto habitacional foi depredado e não possui condições de reforma.

Imagem 8. Obras inacabadas, entre Santa Guilhermina, Magé e Manilha, Itaboraí ..

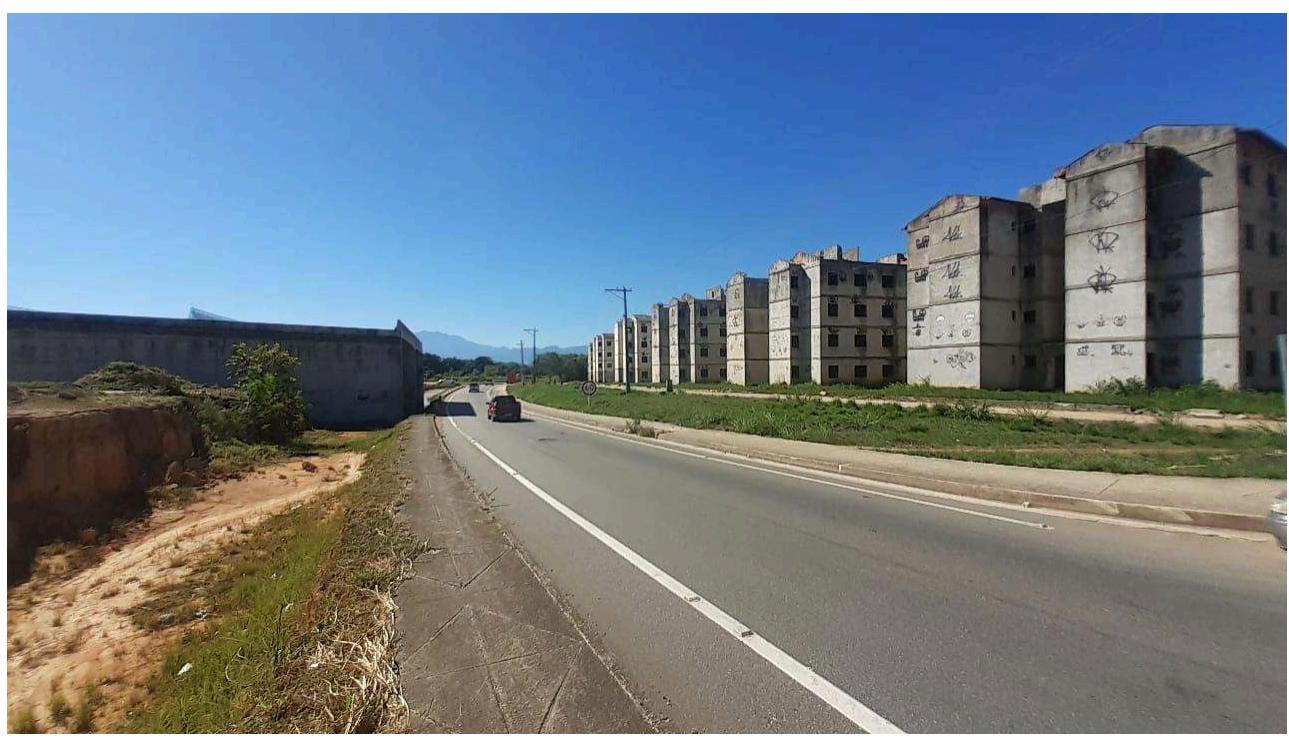

Fonte: CANDIDO, D'Jeanine. (abr, 2021)

Apesar do trecho possuir $25 \mathrm{~km}$ de extensão, o objetivo é a finalização da duplicação de $7 \mathrm{~km}$ e 3 passagens inferiores com previsão para o término das obras em dezembro de 2021. Somente com a finalização total da duplicação, fortalecerá a integração com os eixos modais do Açu, em direção ao Norte do estado e ao multimodal Rio-Minas.

Portanto, o Arco Metropolitano finalizado será uma âncora logística que fará suporte ao circuito produtivo de petróleo e gás do estado, integrando projetos como o Polo GásLub, 
em Itaboraí, a REDUC, Porto de Itaguaí, Porto de Jaconé e empresas do setor naval, conjuntamente com offshore, estaleiros e distritos industriais (PESSANHA, 2019). Conforme a demanda de fluxo desses Grandes Projetos de Investimentos (GPI's), há possibilidade, ainda, de ampliação do projeto do Arco Metropolitano, em direção à Maricá. (SETRANS,2016).

\section{Considerações finais}

Nossa compreensão deste processo de alteração nas redes de mobilidade nos revela a questão de como se dá a vinculação da instalação de novas redes técnicas (sejam elas rodovias, ferrovias, eletrificação entre outros) e suas implicações entre fixos e fluxos e efeitos dessas mudanças no território. Como já mencionamos, os GPI's e redes técnicas são resultados de uma reestruturação espacial que modificam o uso do território e formam novas centralidades.

Para a finalização do Arco Metropolitano, a última etapa é a duplicação e restauração da BR 493, conjuntamente com a integração logística e novas alças de acesso no Trevo de Manilha. Mas, chama a nossa atenção o fato de que o interesse por parte dos agentes públicos do estado do Rio de Janeiro, somente retoma a pauta quando adicionada a uma futura concessão. O que está em questão é a entrega das redes de infraestruturas nacionais nas mãos de empresas privadas, nacionais e/ou estrangeiras, voltadas ao lucro de acionistas, com a perda de hegemonia dos ativos estratégicos do país, sem a contrapartida com as reais responsabilidades ambientais e sociais.

As concessões ocorrem sobre a justificativa de baixa arrecadação e recessão econômica, porém estão sendo feitas principalmente em um momento de desinvestimento no país, que ocorre desde mudança da concepção política de ação do Estado, a partir do golpe de 2016. Ou seja, são redes que serão apropriadas para atender demandas específicas, após estratégias de desvalorização da malha, como abandono e violência.

Logo, esses ativos passam a ter menor valor nos leilões, favorecendo o interesse empresarial em detrimento do social. Isso porque, há um foco em mobilizar concessões e não há planos claros de investimentos em novas infraestruturas. A falta na ampliação na dinamização dos fluxos para uma evolução das (malhas) redes técnicas no ERJ ainda carece de integração entre os diferentes modais de transporte.

\section{BIBLIOGRAFIA}

ARROYO, M. Redes e circulação no uso do território. In: ARROYO, M; CRUZ,R. de C.A. da. Território e circulação: a dinâmica contraditória da globalização. São Paulo: Annablume, 2015.

ANTT. Programa De Exploração da Rodovia (PER) - Rodovia BR-116/RJ TRECHO: Além Paraíba - Teresópolis - Entr. BR-040(A). ANTT, 25/08/2010. Disponível em: https://portal.antt.gov.br/documents/ 359170/1229665/PER+-+Atualizado.pdf/d3bf8bb3-16e6-834c-5cf8-6a08e01ef437?t=1594304014473 $<$ Acesso em: 06/2021> 
ANTT. Programa De Exploração da Rodovia (PER) - BR-116/RJ/MG, BR-465/RJ e BR-493/RJ. ANTT, 2020. Disponível em: https://portal.antt.gov.br/br-116-465-493-rj-mg <Acesso em: 06/2021.

BRASIL. Relatório executivo - Plano Nacional de Logística - 2035. Brasília: Ministério da Infraestrutura, Empresa de Planejamento e Logística,2021. Disponível em: ttps://ontl.epl.gov.br/wp-content/ uploads/2021/10/PNL_2035_Relatorio_Executivo.pdf <Acesso em: 25/10/2021>

CANAL ANTT. Transmissão ao vivo da Audiência Pública nº 11/2020. Canal ANTT (You tube). Dia 15 de janeiro de 2021. Disponível em: https://youtu.be/feBGYMfTeqw < Acesso em: 03/2021>

CANDIDO, D’Jeanine. As transformações espaciais resultantes da inserção de redes técnicas em São Gonçalo: o Sistema UHOS (Ultra Heavy Over Size) e a sua refuncionalização com o projeto Cidade da Pesca. Espaço e Economia [Online], 15 | 2019: http://journals.openedition.org/espacoeconomia/7063

CASTILHO, D. Modernização Territorial e redes técnicas em Goiás. Goiânia: Editora UFG, 2016.

GONZAGA, Bernardo. Governo exclui Casa da Moeda de lista com 18 projetos para privatizações. Poder 360, 25.ago.2021 .Disponível em: https://www.poder360.com.br/economia/governo-exclui-casa-damoeda-de-lista-com-18-projetos-para-privatizacoes/ <Acesso em: 09/2021>

HARVEY, D. Condição pós-moderna. 25ª Ed. São Paulo: Edições Loyola, 2014 [1989].

DIAS, Leila C. Os sentidos da rede: notas para discussão. In: DIAS, L. C.; SILVEIRA, R. L. L. (Orgs.). Redes, sociedades e territórios. 2. ed. Santa Cruz do Sul: Edunisc, 2007.

LENCIONI, S. Metropolização do espaço e a constituição de megarregiões. In: FERREIRA, A., RUA, J.; MATTOS, R. C. Desafios da Metropolização do Espaço. Rio de Janeiro: Consequência, 2015.

MINFRA. INFRA WEEK - Faltam duas semanas para os 28 leilões que vão injetar $R \$ 10$ bilhões de investimentos na infraestrutura do Brasil. MINFRA - Ministério da Infraestrutura, 23.mar.2021. Disponível em: - https://www.gov.br/infraestrutura/pt-br/faltam-duas-semanas-para-os-28-leiloes-quevao-injetar-r-10-bilhoes-de-investimentos-na-infraestrutura-do-brasil-1 < Acesso em: 29/09/2021.>

OLIVEIRA, Floriano J. G. CANDIDO, D'Jeanine. Investimentos produtivos, territorialidades e gestão do uso do território no leste metropolitano do Rio de Janeiro. In: BINSZTOK, Jacob; BARBOSA, Jorge L (ORGS). Modernização Fracassada: Dossiê Comperj. Rio de Janeiro: Consequência/ FAPERJ, 2018.

OLIVEIRA, F. J. G.; OLIVEIRA, L. D. Circuitos Espaciais da Produção e economia do petróleo o Estado do Rio de Janeiro: As transformações territoriais por ação dos níveis superiores da economia. Revista GeoUECE, [S. l.], v. 9, n. 16, p. 09-32, 2020. Disponível em: https://revistas.uece.br/index.php/ GeoUECE/article/view/3206. Acesso em: 11/2020.

RAFFESTIN, Claude. As redes e o poder. In: _. Por uma Geografia do poder. São Paulo: Ática, 1993. (p. 200-220)

RUFINO, Márcio. Redes técnicas, territórios e escalas: Leituras sobre modernização e crítica da economia política do espaço. In: OLIVEIRA, F. J. G; OLIVEIRA, Leandro D. de; TUNES, Regina H; PESSANHA, Roberto M.(org). Espaço e economia: geografia econômica e a economia política. - Rio de Janeiro: Consequência, 2019.

SANTOS, Milton. Por uma geografia das redes. In: A natureza do espaço: técnica e tempo/razão e emoção.4 Ed. São Paulo: Hucitec,2009[1996].

SETRANS. PELC RJ 2045 - Plano Estratégico de Logística e Cargas do estado do Rio de Janeiro. Rio de Janeiro: Secretaria de transportes do Governo do Estado do Rio de Janeiro, 2016. Disponível em: http://www.pelcrj2045.rj.gov.br/biblioteca.asp <Acesso em: 08/2021

SILVEIRA, Márcio R. Os efeitos das concessões aeroportuárias no Brasil entre 2012 a 2018.

GEOSUL. Geosul, Florianópolis, v. 34, n. 70, p. 87-112, jan./abr. 2019. Disponível em: https:// 
periodicos.ufsc.br/index.php/geosul/article/view/2177-5230.2019v34n70p87/38513. Acesso em: $05 / 2021$

PEREIRA DE SOUZA, V. H., \& SILVEIRA, M. R. Organização espacial das redes de transportes e comunicações na América do Sul: uma análise baseada nas revoluções logísticas. Revista Transporte Y Territorio, (21), 118-139. 2019. Disponível em: https://doi.org/10.34096/rtt.i21.7149. Acesso em: $05 / 2021$

PESSANHA, Roberto.M; OLIVEIRA, Floriano J.G. Os circuitos Espaciais de produção do petróleo no Rio de Janeiro e em São Paulo: formação e integração da megarregião RJ-SP. Revista GEOgraphia. Vol.21; n.40, 2019.

TINOCO, Victor. Arco metropolitano do Rio de Janeiro: Transformações e Representações, [S.l.], n. 14, p. 94-117, set. 2019. ISSN 2317-8825. Disponível em: <https://www.revistacontinentes.com.br/index.php/ continentes/article/view/234>. Acesso em: 14 jul. 2021.

\section{NOTAS}

1. O Arco Metropolitano foi construído entre 2007-2014, com objetivo de integração regional para o fluxo de cargas e produção. Ele possui importância de integração de polos estratégicos como as infraestruturas do antigo projeto do Comperj(Atual Polo Gaslub), a Reduc, ao Porto de Itaguaí e seu distrito industrial, além do acesso a 5 grandes grandes eixos rodoviários federais: Rio-Vitória (BR101 norte), Rio-Bahia, a BR040 que liga a cidade do Rio de Janeiro a Juiz de Fora/MG, a BR 495 (antiga RJ-SP) e a BR 101 SUL (RJ a Santos/SP) entre outras interseções com outras vias locias.

2. Segundo Castilho, a modernização não se aplica exclusivamente ao moderno, mas também se alimenta do atraso

3. Artigo originalmente publicado no XIV Encontro Nacional de pós-graduação e pesquisa em Geografia, (2021).

4. O projeto do Comperj (complexo petroquímico) foi reduzido para o projeto do Polo Gáslub Itaboraí a a partir de 2019. Esse projeto tem como objetivo a finalização de uma Unidade de Processamento de Gás Natural (UPGN) - atualmente em construção-, ao qual alimentará uma termelétrica a gás natural, também terá um setor de processamento de lubrificantes, com a interligação das infraestruturas já existenctes da REDUC. O projeto prevê o investimento de grandes empresas internacioanis como a Qatargas, GE Power e Taqa.

5. Audiência Pública no 11/2020. - Realizada no dia 15/01/2021 - https://participantt.antt.gov.br/ Site/AudienciaPublica/VisualizarAvisoAudienciaPublica.aspx?CodigoAudiencia $=440$. Acesso em: $15 / 03 / 2021$

6. Municípios localizados a leste da região metropolitana fluminense, como Niterói, São Gonçalo, Itaboraí, Maricá, Tanguá, Cachoeira de Macacu, Guapimirim, Rio Bonito e Magé. Essa regionalização tem fim de análise e não administrativo.

7. Atualmente, o novo contrato de concessão foi aumentado para 30 anos e adicionado mais 223,8 km de trechos da BR 101 Sul (de Campo Grande, no Rio de Janeiro, à Praia Grande, em São Paulo). O leilão ocorreu em 29/10/2021, e tem como objetivo o início do contrato no $1^{\circ}$ trimestre de 2022. Mais um "período de leilões" que previstos para o mês de novembro, nomeado \#SuperInfraMonth.

8. Fonte: https://www.agenciainfra.com/blog/oito-empresas-pedem-para-conhecer-mudancasnos-estudos-para-relicitacao-da-dutra/ e https://oglobo.globo.com/economia/novo-contrato-deconcessao-da-via-dutra-ja-tem-9-empresas-interessadas-diz-freitas-24505943

9. Nome da concessionária que obteve a concessão. Esse segmento esteve associado ao primeiro contrato de concessão adquirido em 1995, que partia do município de Magé à Teresópolis. Contudo, em menos de um ano, em 1996, foi adicionado ao trecho até a divisa do RJ com MG. 
10. Entre Duque de Caxias e Magé há uma sobreposição da BR 116 com o Arco Metropolitano (BR 493). que é nomeado como Rodovia Santos Dumont, que se estende do Km 0 no Ceará até o entroncamento com a BR 040 na cidade do Rio de Janeiro.

11. A partir de março de 2021, a concessionária estendeu o prazo de concessão original por mais 18 meses até que finalizasse o novo processo de concessão Rio -Valadares. ( $5^{\circ}$ Termo Aditivo ao Contrato de Concessão no PG156/95-00)

12. Havia uma praça em Três Córregos no km 71, em Teresópolis, mas que está com a cobrança suspensa desde 02 de setembro de 2009.

13. Valores estipulado desde março de 2021 , sendo que nas praças auxiliares são cobrados $\mathrm{R} \$ 13,10$.

14. Projeto de concessão do Estado do Rio de Janeiro nomeado "Facilita RJ", inclui estudos para as rodovias RJ-127, RJ-158, RJ-160 e RJ-186 (Eixo Noroeste) e RJ-244, com prazo de 25 anos. A rodovia RJ-122, ainda está em análise para possível potencial de concessão. Atualmente, o projeto está em fase de estudo e a previsão da licitação e contratação está para 2022. Fonte: http://rj.gov.br/ NoticiaDetalhe.aspx?id_noticia=14136

15. Ação civil pública № 5000622-48.2021.4.02.5114/RJ

16. Lei $\mathrm{n}^{\mathrm{o}} 13.334$, de 2016 .

17. Eram projetos do governo federal. O PAC foi criado em 2007 com o objetivo em obras de infraestrutura e de Grandes Projetos de Investimentos no país e o Programa de Investimento e Logística foi criado em 2012, a fim de aumentar o investimento na malha rodoviária e ferroviária nacional. Fonte: http://g1.globo.com/economia/noticia/2016/06/infraestrutura-depende-daampliacao-das-concessoes-dizem-especialistas.html

18. Exemplo, Porto de São Sebastião (SP), imóveis do Serpro, da Companhia Docas do Espírito Santo (Codesa) e da Empresa Gestora de Ativos (Emgea)

19. Na Infraweek, foram leiloados 22 aeroportos, 5 terminais portuários, a Ferrovia de Integração Oeste-Leste (FIOL I) e a BR-153/080/414/GO/TO.

20. Exceto a BR-153/080/414/GO/TO que é de 35 anos.

21. https://www.ppi.gov.br/projetos1\#/s/Em\%20andamento/u//e/Rodovias/m//r/

22. O projeto compreende a Rodovia BR 116 (RMRJ), conhecida como Via Dutra o primeiro trecho de 46km, entre o entroncamento do Trevos das Margaridas (na Avenida Brasil), BR 101, na cidade do Rio de Janeiro com o entroncamento com a BR465 em Seropédica. Esse trecho pertencia à concessão da "Nova Dutra" que se estendia do Rio até São Paulo. O segundo trecho com 146,3 km, entre o entroncamento com a BR393, no Distrito de Jamapará e o entroncamento da BR040/493/ RJ109, em Duque de Caxias. Na BR 493, o atual Arco metropolitano, possui dois trechos, um com $26 \mathrm{~km}$, entre o entroncamento com a BR101 em Manilha, em Itaboraí e o entroncamento com a BR116, em Santa Guilhermina, em Magé. E o segundo trecho, com 75,6km entre Duque de Caxias, no entroncamento da BR040/116(B) e Porto de Itaguaí, com 22,8km. Na BR-465/RJ, entre o entroncamento com a BR-116 e o entroncamento com a BR-101 (22,8 km). E por fim, a BR-116/ MG, entre o entroncamento com a BR-381/451, em Governador Valadares (MG), e a divisa dos Estados de Minas Gerais e Rio de Janeiro (409,6 km).

23. Os $191 \mathrm{~km}$ são divididos entre as concessionárias CCR Nova Dutra ( $45 \mathrm{~km})$ entre a cidade do Rio de Janeiro e Seropédica e CRT (146 km) entre Duque de Caxias até a divisa do ERJ com MG.

24. Segundo a ANTT são 536,6 km de pista simples e 190,3 $\mathrm{km}$ de pista dupla, totalizando 726,9 $\mathrm{km}$.

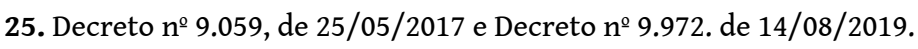

26. Sob análise do TCU. Fonte: https://www.abdib.org.br/2021/06/30/projeto-para-concessaode-pedagios-na-br-116-em-guapimirim-esta-sob-analise-do-tcu/

27. Esse mesmo critério será utilizado na nova concessão da BR 116 (RJ/SP), considerado pelo governo o maior leilão do ano.

28. Lei $14.157 / 2021$ 
29. Porto de Niterói/RJ, Píer de Itaóca (São Gonçalo,RJ), Porto de Jaconé em Maricá/RJ (previsto para 2022), Porto de Imbetiba(Macaé,RJ), Porto do Açu

30. Obras iniciadas no dia 30/07/2021, para duplicação nos $\mathrm{km} 0,80$ ao 5,30 e doa $\mathrm{km} 17,60$ ao 18,80 e finalização de pontes nos $\mathrm{km} \mathrm{2,0} ; 3,50 ; 5,00$.

\section{RESUMOS}

Este artigo trata das mudanças territoriais no leste metropolitano do Rio de Janeiro após a construção e duplicação de rodovias para atender a demanda de Grandes Projetos de Investimento. Esses projetos resultaram em vários estudos logísticos como a PELC RJ 2045, que objetivam a melhor circulação interestadual e intraestadual de cargas, insumos, energia, pessoas e etc no estado. No entanto, após a mudança na política nacional a partir de 2016, observa-se a modificação de projeto para se iniciar a expansão de concessões e relicitações de rodovias estratégicas como, a BR 101, BR 116 e o Arco Metropolitano. Desse modo, este estudo está centrado na identificação dos planos governamentais voltados à entrega desses ativos públicos à iniciativa privada, como o eixo logístico Rio-Governador Valadares e a relicitação da Nova Dutra, um dos trechos mais movimentados do estado.

This article deals with territorial changes in the metropolitan east of Rio de Janeiro after the construction and duplication of highways to meet the demand for Large Investment Projects. These projects resulted in several logistical studies such as the PELC RJ 2045, which aim to improve the interstate and intrastate circulation of cargo, supplies, energy, people, etc. in the state. However, after the change in national policy from 2016 onwards, there is a change in the project to start the expansion of concessions and re-bidding of strategic highways such as BR 101, BR 116 and the Arco Metropolitano. Thus, this study is focused on identifying government plans aimed at delivering these public assets to the private sector, such as the Rio-Governador Valadares logistical axis and the re-bidding of Nova Dutra, one of the busiest stretches of the state.

Cet article étudie les changements territoriaux dans l'est métropolitain de Rio de Janeiro depuis la construction et le doublement des autoroutes liés aux Grands Projets d'Investissement. Ces projets sont à l'origine de plusieurs études logistiques tels que la PELC RJ 2045, dont l'objectif est d'améliorer la circulation de gens, de marchandises et d'énérgie si entre les états qu'à l'intérieur de l'état de Rio. Cependant, après les changements au niveau nationale en 2016, on constate le début de l'expansion des concessions et de licitations de autoroutes stratégiques comme les BR-101, BR-116 et l'Arc Métropolitain. Dans ce cadre, on veut aussi comprendre les plans gouvernementaux voués à transmettre ces actifs publiques à l'initiative privée tels que l'axe logistique Rio-Governador Valadares et la nouvelle licitation de la Nova Dutra --- l'une des sections les plus agitées de l'état.

Este artículo trata de los cambios territoriales en el este metropolitano de Río de Janeiro después de la construcción y duplicación de carreteras para atender la demanda de Grandes Proyectos de Inversión. Estos proyectos dieron como resultado varios estudios logísticos como PELC RJ 2045, que tienen como objetivo mejorar la circulación interestatal e intraestatal de carga, suministros, energía, personas, etc. en el estado. Estos proyectos dieron como resultado varios estudios logísticos como PELC RJ 2045, que tienen como objetivo mejorar la circulación interestatal e 
intraestatal de carga, suministros, energía, personas, etc. en el estado. Sin embargo, tras el cambio de política nacional a partir de 2016, el proyecto fue modificado para iniciar la ampliación de concesiones y relicitaciones de carreteras estratégicas como la BR 101, la BR 116 y el Arco Metropolitano. Así, este estudio se centra en la identificación de los planes gubernamentales destinados a la entrega de estos bienes públicos al sector privado, como el eje logístico RioGovernador Valadares y la relicitación de Nova Dutra, uno de los tramos más transitados del estado.

\section{ÍNDICE}

Keywords: highway concessions; technical networks; infrastructure; logistics; Rio de Janeiro. Palabras claves: concesiones de carreteras; redes técnicas; infraestructura; logística; Rio de Janeiro.

Palavras-chave: concessões rodoviárias ; redes técnicas; infraestrutura; logística; Rio de Janeiro. Mots-clés: concessions autoroutières ; réseaux techniques ; infrastructure ; logistique ; Rio de Janeiro.

\section{AUTOR \\ D'JEANINE CANDIDO}

Mestranda em Políticas Públicas e Formação Humana (PPFH/UERJ) e graduada em Geografia pela Universidade do Estado do Rio de Janeiro. E-mail: djeaninecandido@gmail.com 